\title{
The Oral Health Knowledge and Self-care Practices of Pregnant Women in Saudi Arabia
}

\author{
Salma Moawed ${ }^{1}$, Amany S. Badawy $y^{2,3, *}$, Samar Alotaibi ${ }^{3}$, Maha Alrowily ${ }^{4}$ \\ ${ }^{1}$ Department of Maternity \& Child health Nursing, College of Nursing, King Saud University, KSA \\ ${ }^{2}$ Maternal and Newborn Health Nursing, College of Nursing, Zagazig University, Egypt \\ ${ }^{3}$ Maternal and Newborn Health Nursing, College of Nursing King Saud University, KSA \\ ${ }^{4}$ Maternity and Gyn. Nursing, College of Nursing, King Saud University, KSA \\ *Corresponding author: dramanys@hotmail.com
}

Received March 17, 2019; Revised April 22, 2019; Accepted June 15, 2019

\begin{abstract}
Background. Pregnancy is a unique time in a woman's life and is characterized by complex physiological changes. These changes can adversely affect oral health. Oral health is a state of being free from chronic mouth and facial pain, oral and throat cancer, oral sores, periodontal (gum) disease, tooth decay and tooth loss, and other diseases, and disorders that affect the oral cavity. Risk factors for oral diseases include unhealthy diet, tobacco use, harmful alcohol use, and poor oral hygiene (WHO). Multiple studies have shown an association between periodontal infection and adverse pregnancy outcomes, such as premature delivery and low birth weight. Aim of this study assess women's knowledge towards oral and dental health during pregnancy and to examine their self-care practices in relation to oral and dental health. Methodology The research will be conducted at randomly governmental primary health care centers and schools in Riyadh (Dawadmi region). A Quantitative Descriptive cross-sectional study was carried out. two-hundred Saudi pregnant women selected randomly. Women who gave informed consent were asked to complete a self-administered questionnaire and return it to the researcher A Structured questionnaire will be developed consisted of three parts, Demographic characteristics part, level of women`s Knowledge regarding oral health part \& Self-care practice regard oral health care. Results, Conclusion \& Recommendation. Age of participant women's between $28-38$ years (43.2\%). Most of the participants had number of pregnancies between 4-6 (38.5\%). Regarding the level of knowledge about oral health, this study showed that $45 \%$ of mother had poor knowledge, and there is a significant relationship between the level of practice and the educational, professional status and attendance to antenatal clinic, which was started by $65 \%$ of the sample on time, however, they did not visit the dentist. This study recommends that the implementation of oral health programs in prenatal services is essential to delivery of dental care and decreasing the potential oral problems among pregnant women, as well as conducting careful screening of oral risks, and assisting women in obtaining regular dental care.
\end{abstract}

Keywords: oral health, knowledge, self-care practice, pregnant women

Cite This Article: Salma Moawed, Amany S. Badawy, Samar Alotaibi, and Maha Alrowily, "The Oral Health Knowledge and Self-Care Practices of Pregnant Women in Saudi Arabia.” American Journal of Nursing Research, vol. 7, no. 4 (2019): 643-651. doi: 10.12691/ajnr-7-4-25.

\section{Introduction}

Oral health is a state of being free from a chronic mouth and facial pain, oral and throat cancer, oral sores, birth defects such as cleft lip and palate, periodontal (gum) disease, tooth decay and tooth loss, and other diseases and disorders that affect the oral cavity. Risk factors for oral diseases include unhealthy diet, tobacco use, harmful alcohol use, and poor oral hygiene [1] Women need to be aware of the importance of oral health care during and after pregnancy for themselves as well as their children. Early education programs aimed at pregnant women can help to prevent oral diseases in both mother and infant. Dental professionals can play an important role in assuring the well-being of women during their pregnancies by promoting and maintaining their oral health [1,2].

Studies have confirmed the safety and effectiveness of providing oral health care during pregnancy. Pregnancy by itself is not a reason to defer routine dental care and necessary treatment for oral health problems. Diagnosis and treatment, including dental X-rays, can be undertaken safely during the first trimester of pregnancy. Treatment can be provided throughout pregnancy; however, the time period between the 14th and 20th week is considered ideal. [3].

Periodontal diseases produce a wide range of clinical signs and symptoms such as tooth loss, altered appearance, pain, bleeding, bad breath and impaired quality of life $[4,5,6]$. Loss of posterior occluding supports has been associated with impaired chewing efficiency and inadequate nutrition [7] which may result in the loss of important 
nutrients due to over preparation of food in order it easier to eat. Inadequate nutrition during pregnancy may lead to poor fetal growth and possibly interfere with kidney development which in turn leads to raised blood pressure in adulthood. Other changes associated with pregnancy include chloasma, facial telangiectasia, sialorrhea, tooth surface loss usually related to vomiting when severe (hyperemesis gravidarum), increased mobility of teeth and oral aphthate $[8,9,10]$.

Morning sickness is a common problem which is encountered by women, early in their pregnancies. The gastric acids which are present in the emesis, erode the enamel on the inner surface of the teeth, most commonly the front teeth [11]. This is a concern only in the cases with frequent vomiting, for example, in bulimics and in patients with hyperemesis gravidum. Erosion of the enamel can easily be controlled by advising the patients to rinse their mouths thoroughly after vomiting, with a solution that contains sodium bicarbonate. Sodium bicarbonate neutralizes the acids and it prevents the damage which is caused by the residue which remains on the teeth. Erosion of the teeth which are on the lingual and palatal surfaces of the incisors was mentioned in a case report, but as per our knowledge, there is no clinical study which is available to support this finding $[12,13,14]$.

Checking the salivary estrogen level has been suggested as a screening test to detect the risk potential for preterm labor. The recent studies have suggested a link between periodontal disease and preterm low birth weight. The periodontal disease seemed to be independent of good oral hygiene and a periodontal treatment [15,16].

The opinions of nursing practitioners and certified nurse midwives on oral health care for pregnant women were also sought by the North Carolina research group. Among 219 nurses, 86\% reported referring patients for dental health screening; many showed equivocal information regarding the more favorable prenatal trimester to initiate dental treatment but admitted the need to collaborate with dental professionals to reduce risks during pregnancy [4].

\subsection{Aim of the Study}

Assess women's knowledge towards oral and dental health during pregnancy and to examine their self-care practices in relation to oral and dental health.

\subsection{Research Questions}

1. How knowledgeable are Saudi pregnant women about oral health care?

2. What are the oral hygiene habits and practices of Saudi pregnant women in Riyadh?

\subsection{Study Methodology}

\subsubsection{Research Design}

A Quantitative descriptive cross-sectional study was carried out.

\subsubsection{Setting}

The research was conducted at randomly selected governmental primary health care centers and schools in Riyadh and Dawadmi region.

\subsubsection{Sampling}

Sample type:

Multi stage random sample.

Sample Size:

200 pregnant women

Sample Criteria:

Inclusion criteria:

1. Saudi women.

2. All pregnancy periods.

Exclusion criteria:

1. Mothers with diabetic.

2. Non- Saudi

\subsection{Tools of Data Collection}

A Structured questionnaire will be developed by the researcher to collect data after the review of literature. It consists of 3 parts: Part One will cover the demographic characteristics such as: age, marital status, number of children, level of education, parent level of education, Ideal number of children desired Part two will cover the: level of women`s Knowledge regarding oral health knowledge close-ended questions. Part three will cover the Self-care practice regard oral health care.

\subsection{Testing instrument}

a. Pilot study: will be carried out on 7 participants to evaluate the validity of the tool, which will be used in this study for data collecting and accordingly necessary modification will be done. The participants who will be tested as pilot study will be excluded from the study sample.

b. Expert Evaluation: content validity of the questionnaire will be tested through review by 5 experts from the same field in order to prove the relevancy of questionnaire statement to the study objectives.

\section{Results}

Table 1. Distribution of the Saudi pregnant women according to their socio-demographic characteristic $(n=200)$

\begin{tabular}{|l|c|c|}
\hline Parameter & Frequency & Percent \% \\
\hline Age & 36 & 18.1 \\
$17-27$ & 86 & 43.2 \\
$28-38$ & 77 & 38.7 \\
$39-49$ & & \\
\hline Educational level & 6 & 3.0 \\
primary-secondary & 15 & 7.5 \\
intermediate & 49 & 24.6 \\
secondary & 129 & 64.8 \\
academic & 142 & \\
\hline Professional status & 56 & 71.7 \\
Employee & & 28.3 \\
housewife & 36 & 18.3 \\
\hline Income status & 83 & 42.1 \\
less than 5000 SR & 78 & 39.6 \\
5000 to 10000 SR & & \\
10000 and more SR & 22 & 11.3 \\
\hline The number of family members & 117 & 60.3 \\
1-3 & 43 & 22.2 \\
4-7 & 12 & 6.2 \\
8-10 & & \\
$11-15$ & & \\
\hline
\end{tabular}


Table 1 shows the socio-demographic characteristics of the participants. Most participants, 86 (43.2\%), were aged between 28-38 years old participant and most of them from university-level education were 64.8\%. About 71.7 of participants were employed the participants were asked to rate their family income was less than 5000, from 5000-10000, from 10000 and more about (42.1) their family income from 5000 to 10000 , (39.6) considered their income from 10000 and more, (18.3) considered their income less than 5000. Majority of participant s (60.3) have number of family from 4-7, (22.2) of participant have number of family from $8-10$.

Table 2. Distribution of the Saudi pregnant women according to their obstetrical history: $(n=200)$

\begin{tabular}{|l|c|c|}
\hline Parameter & Frequency & Percent \% \\
\hline Number of pregnancies & 71 & \\
$1-3$ & 75 & 36.4 \\
$4-6$ & 36 & 38.5 \\
$7-9$ & 13 & 18.5 \\
$10-13$ & 78 & 6.7 \\
\hline numbers of deliveries & 83 & 39.8 \\
$1-3$ & 25 & 12.3 \\
$4-6$ & 10 & 5.8 \\
$7-9$ & & \\
$10-13$ & 51 & 47.2 \\
\hline number of abortion & 15 & 13.9 \\
Once & 10 & 9.3 \\
Twice & 32 & 29.6 \\
three times & & \\
Others & 74 & 40.2 \\
\hline The number of living children & 79 & 42.9 \\
$1-3$ & 23 & 12.5 \\
$4-6$ & 8 & 4.3 \\
$7-9$ & & \\
$10-13$ & 174 & 88.8 \\
\hline do you go for antenatal care clinic & 22 & 11.2 \\
Yes & & \\
No & 114 & 61.6 \\
\hline The month go to care for pregnancy & 33 & 17.8 \\
first 3 months of pregnancy & 38 & 20.5 \\
mid 3 months of pregnancy & & \\
last 3 months of pregnancy & & \\
\hline
\end{tabular}

Table 2 shows the obstetrics characteristics of the participants. Most of participants had number of pregnancies between 4-6 they were 75 (38.5). About (42.3) considered their number of deliveries from 4 to 6 , the majority of participants, (47.2) had once previous abortion,
(40.2) considered the number of living children from 1- 3 whilst (42.9) the number of their children from 4 to 6 ). Most of the participants, 174 (88.8\%), were go to antenatal care clinic and the month they go to the antenatal care in the first 3 months of pregnancy they were 114 (61.6).

Table 3 show the chronic disease and past surgical history of participants A majority of participants (83.3) were didn't complained from chronic diseases whilst (16.7) participants complained from chronic diseases, about (50.0) were complained from hypertension, (10.0) were complained from Gingivitis (5.0) were complained from Asthma. The Majority of the participants, (63.1) answered with a "no" about past surgical history, (52.3) of participants have cesarean sections.

Table 3. Distribution of the Saudi pregnant women according to their chronic disease and past surgical history $(\mathrm{n}=200)$

\begin{tabular}{|c|c|c|}
\hline Parameter & Frequency & Percent \% \\
\hline $\begin{array}{l}\text { Do you suffer from chronic diseases } \\
\text { - Yes } \\
\text { - No }\end{array}$ & $\begin{array}{c}33 \\
165\end{array}$ & $\begin{array}{l}16.7 \\
83.3\end{array}$ \\
\hline $\begin{array}{l}\text { if yes, indicate the disease } \\
\text { - Asthma } \\
\text { - Colon } \\
\text { - Gingivitis } \\
\text { - Hypertension } \\
\text { - Hypertension and hypothyroidism } \\
\text { - Hypothyroidism } \\
\text { - Sinusitis }\end{array}$ & $\begin{array}{c}1 \\
1 \\
2 \\
10 \\
1 \\
4 \\
1\end{array}$ & $\begin{array}{c}5.0 \\
5.0 \\
10.0 \\
50.0 \\
5.0 \\
20.0 \\
5.0\end{array}$ \\
\hline $\begin{array}{l}\text { Have you ever did surgery } \\
\bullet \text { Yes } \\
\cdot \text { No } \\
\end{array}$ & $\begin{array}{c}73 \\
125\end{array}$ & $\begin{array}{l}36.9 \\
63.1 \\
\end{array}$ \\
\hline $\begin{array}{l}\text { if yes specify } \\
\text { - Adenoids } \\
\text { - Appendix } \\
\text { - Caesarean section } \\
\text { - Caesarean section and Gallstones } \\
\text { - Dilation and curettage } \\
\text { - Gallstones } \\
\text { - Heart surgery } \\
\text { - Hernia } \\
\text { - Myopia } \\
\text { - Sebaceous cyst }\end{array}$ & $\begin{array}{c}1 \\
5 \\
34 \\
2 \\
5 \\
9 \\
1 \\
4 \\
1 \\
3\end{array}$ & $\begin{array}{c}1.5 \\
7.7 \\
52.3 \\
3.1 \\
7.7 \\
13.8 \\
1.5 \\
6.2 \\
1.5 \\
4.6\end{array}$ \\
\hline
\end{tabular}

Table 4. Distribution of the Saudi pregnant women according to their general knowledge about oral health (n=200)

\begin{tabular}{|c|c|c|c|c|c|c|}
\hline \multirow{2}{*}{ Question (knowledge ) } & \multicolumn{2}{|c|}{ Yes } & \multicolumn{2}{|c|}{ No } & \multicolumn{2}{|c|}{ I don't know } \\
\hline & No & $\%$ & No & $\%$ & No & $\%$ \\
\hline $\begin{array}{l}\text { 1-pregnant women are faced with a new situation from all areas; health, } \\
\text { psychological and hormonal which affects the health of the mouth and teeth }\end{array}$ & 150 & 75.8 & 21 & 10.6 & 27 & 13.6 \\
\hline $\begin{array}{l}\text { 2-the importance of oral and dental care begins before pregnancy to reduce } \\
\text { dental problems during pregnancy }\end{array}$ & 155 & 77.9 & 15 & 7.5 & 29 & 14.6 \\
\hline 3-Gum disease in pregnant women more than non-pregnant women & 136 & 68.0 & 23 & 11.5 & 41 & 20.5 \\
\hline 4-change in the hormones during pregnancy have negative effect on the gum & 120 & 60.0 & 27 & 13.5 & 53 & 26.5 \\
\hline $\begin{array}{l}\text { 5-Vomiting with nausea in the first months contain acids damage the outer layer } \\
\text { of the teeth }\end{array}$ & 85 & 42.5 & 30 & 15.0 & 85 & 42.5 \\
\hline 6-pregnant women can visit the dentist for treatment and advice if necessary & 161 & 80.9 & 14 & 7.0 & 24 & 12.1 \\
\hline $\begin{array}{l}\text { 7-pregnant diet affects baby's teeth are healthy since are baby teeth beginning the } \\
\text { fourth month }\end{array}$ & 115 & 59.9 & 10 & 5.2 & 67 & 34.9 \\
\hline 8-calcium deficiency during pregnancy causes necrosis in teeth & 155 & 77.9 & 7 & 3.5 & 37 & 18.6 \\
\hline 9-during your pregnancy you experienced caries and periodontitis & 84 & 42.4 & 114 & 57.6 & 0 & 0.0 \\
\hline 10-do you have children who have dental problems & 78 & 40.0 & 117 & 60.0 & 0 & 0.0 \\
\hline
\end{tabular}


Table 5. Distribution of the Saudi pregnant women according to their general Self-care practice about oral health (n= 200)

\begin{tabular}{|c|c|c|c|c|c|c|}
\hline \multirow{2}{*}{ Question (Self-Care Practice) } & \multicolumn{2}{|c|}{ Yes } & \multicolumn{2}{|c|}{ No } & \multicolumn{2}{|c|}{ I don't know } \\
\hline & No & $\%$ & No & $\%$ & No & $\%$ \\
\hline 1-Brushing teeth after vomiting directly harmful to teeth & 49 & 24.5 & 87 & 43.5 & 64 & 32.0 \\
\hline $\begin{array}{l}\text { 2-Suck some candy to reduce nausea associated with pregnancy during the first months } \\
\text { causing dental caries and gingivitis }\end{array}$ & 88 & 44.9 & 42 & 21.4 & 66 & 33.7 \\
\hline 3-do you have a toothbrush at home to clean teeth & 194 & 97.0 & 6 & 3.0 & 0 & 0.0 \\
\hline 4-do you have a mistake at home to clean teeth & 123 & 61.8 & 76 & 38.2 & 0 & 0.0 \\
\hline 5-clean teeth daily brushing and toothpaste from important things to pregnant & 167 & 83.5 & 16 & 8.0 & 17 & 8.5 \\
\hline 6-flossing is important for maintaining oral hygiene and dental health & 136 & 68.3 & 19 & 9.5 & 44 & 22.1 \\
\hline 7-pregnant women can use mouth wash for mouth and health and protection from lime & 122 & 61.3 & 20 & 10.1 & 57 & 28.6 \\
\hline $\begin{array}{l}\text { 8-Eat a balanced diet of bread, cereals, fruit and vegetables, meat, fish and milk and the milk } \\
\text { was important for strengthening and protecting the teeth from decay }\end{array}$ & 170 & 85.4 & 10 & 5.0 & 19 & 9.5 \\
\hline 9-frequent snacks containing carbohydrates and sugars increase the likelihood of tooth decay & 145 & 72.5 & 31 & 15.5 & 24 & 12.0 \\
\hline 10-do you use herbal medicines to cure the problem of your teeth during pregnancy & 24 & 12.1 & 174 & 87.9 & 0 & 0.0 \\
\hline 11-Have you ever gone to dental clinic during pregnancy & 69 & 34.8 & 129 & 65.2 & 0 & 0.0 \\
\hline 12-is dental fillings during pregnancy & 43 & 21.8 & 154 & 78.2 & 0 & 0.0 \\
\hline 13-is remove -one of the teeth during pregnancy & 18 & 9.2 & 178 & 90.8 & 0 & 0.0 \\
\hline
\end{tabular}

Table 4 summarizes the participant's response to the degree of knowledge for pregnant women category which includes ten items. The first item was $75.8 \%$ whom have knowledge and $24.8 \%$ whom have not knowledge. The second item was $77.9 \%$ whom have knowledge and $22.1 \%$ whom have not knowledge. The third item was $68 \%$ whom have knowledge and $32 \%$ whom have not knowledge. The fourth item was $60 \%$ whom have knowledge and $40 \%$ whom have not knowledge. The fifth item was $42.5 \%$ whom have knowledge and $57.5 \%$ whom have not knowledge. The sixth item was $80.9 \%$ whom have knowledge and $19.1 \%$ whom have not knowledge. The seventh item was $59.9 \%$ whom have knowledge and $40.1 \%$ whom have not knowledge. The eighth item was $77.9 \%$ whom have knowledge and $22.1 \%$ whom have not knowledge. The ninth item was $42.4 \%$ whom have knowledge and $57.6 \%$ whom have not knowledge. The tenth item was $40 \%$ whom have knowledge and $60 \%$ whom have not knowledge.

This table summarizes the participant's response of degree of Practice for pregnant women category which includes ten items. The first item was $24.5 \%$ whom have known and doing this Practice and $75.5 \%$ whom have not known and didn't doing. The second item was $44.9 \%$ whom have Practice and 55.1\% whom have not Practice. The third item was $97 \%$ whom have Practice and 3\% whom have not Practice. The fourth item was $61.8 \%$ whom have Practice and $38.2 \%$ whom have not Practice. The fifth item was $83.5 \%$ whom have Practice and $16.5 \%$ whom have not Practice. The sixth item was $68.3 \%$ whom have Practice and $31.7 \%$ whom have not Practice. The seventh item was $61.3 \%$ whom have Practice and $38.7 \%$ whom have not Practice. The eighth item was $85.4 \%$ whom have Practice and $14.6 \%$ whom have not Practice. The ninth item was $72.5 \%$ whom have Practice and $27.5 \%$ whom have not Practice. The tenth item was $12.1 \%$ whom have Practice and $87.9 \%$ whom have not Practice. The eleventh item was $34.8 \%$ whom have Practice and $65.2 \%$ whom have not Practice. The twelfth item was 21.8 \% whom have Practice and $78.2 \%$ whom have not
Practice. The thirteenth item was $9.2 \%$ whom have Practice and $90.8 \%$ whom have not Practice (Table 5).

Presents table shows the association between sociodemographic data and knowledge of pregnant women. A chi-square test was used to test the association of pregnant women knowledge with age and educational level A statistical significant was observed $\left(\mathrm{x}^{2}=0.072\right.$, 0.021 ) respectively. No significant was observed between Professional status and degree of knowledge of pregnant women $\left(x^{2}=0.515, p=0.773\right)$. Also, no significant between level of knowledge and family income status $\left(x^{2}=5.448, p=0.244\right)$ (Table 6).

Regarding the association between obstetric history and degree of knowledge of pregnant women. A chi-square test was used. A statistically significant was observed between level of knowledge and go to antenatal care clinic $\left(x^{2}=5.185, p=0.075\right)$ on the other hand no significant was observed between level of knowledge and numbers of pregnancies, Numbers of deliveries, number of abortion \& The number of living children (Table 7).

Table 8 represent the association between sociodemographic data and degree of self-care Practice of pregnant women. A chi-square test used, no significantly was observed between age, family income and number of family $\left(X^{2}=0.456,0.257 \& 0.298\right)$ respectively. The variable of educational level $\left(x^{2}=15.5, p=0.017\right)$ was significantly associated with level of self-care Practice of pregnant women. A statistical significantly was observed between Professional status and degree of self-care Practice of pregnant women. $\left(x^{2}=6.11, p=0.047\right)$

Presents Table 9 represent the association between Number of pregnancies and degree of self-care Practice of pregnant women. Not significant observed between The of Number of pregnancies and number of deliveries $\left(x^{2}=10.42, p=0.108\right) \quad\left(x^{2}=7.195, p=0.303\right)$ respectively. A chi-square test was used to test was used to test the association of pregnant women self-care Practice level 
with antenatal care clinic. The variable of antenatal care clinic ( $\left.x^{2}=16.47, p=0.00\right)$ was significantly associated with level of Practice of pregnant women. A significant statistical was observed in the association between the months go to care for pregnancy and degree of self-care Practice of pregnant women. $\left(x^{2}=14.815, p=0.005\right)$.

Table 6. Relationship between level of knowledge and Socio-demographic data

\begin{tabular}{|c|c|c|c|c|c|c|}
\hline \multirow{2}{*}{ Items } & \multicolumn{3}{|c|}{ level of knowledge } & \multirow{2}{*}{ Total } & \multirow{2}{*}{$X^{2}$} & \multirow{2}{*}{$\boldsymbol{P}$} \\
\hline & Excellent & very good & Poor & & & \\
\hline \multicolumn{5}{|l|}{ Age (years) } & \multirow{5}{*}{8.609} & \multirow{5}{*}{0.072} \\
\hline$\cdot 17-27$ & 4 & 15 & 17 & 36 & & \\
\hline - 28-38 & 6 & 49 & 31 & 86 & & \\
\hline - 39-49 & 5 & 28 & 44 & 77 & & \\
\hline Total & 15 & 92 & 92 & 199 & & \\
\hline \multicolumn{5}{|l|}{ Educational Level } & \multirow{6}{*}{14.916} & \multirow{6}{*}{$0.021^{*}$} \\
\hline • primary-secondary & 1 & 0 & 5 & 6 & & \\
\hline - intermediate & 0 & 3 & 12 & 15 & & \\
\hline - Secondary & 2 & 25 & 22 & 49 & & \\
\hline - Academic & 12 & 64 & 53 & 129 & & \\
\hline Total & 15 & 92 & 92 & 199 & & \\
\hline \multicolumn{5}{|l|}{ Professional status } & \multirow{4}{*}{0.515} & \multirow{4}{*}{0.773} \\
\hline - Employee & 11 & 68 & 63 & 142 & & \\
\hline - Housewife & 4 & 24 & 28 & 56 & & \\
\hline Total & 15 & 92 & 91 & 198 & & \\
\hline \multicolumn{5}{|l|}{ income status } & \multirow{5}{*}{5.448} & \multirow{5}{*}{0.244} \\
\hline - less than 5000 & 1 & 15 & 20 & 36 & & \\
\hline - 5000 to 10000 & 10 & 37 & 36 & 83 & & \\
\hline - 10000 and more & 4 & 40 & 34 & 78 & & \\
\hline Total & 15 & 92 & 90 & 197 & & \\
\hline \multicolumn{5}{|c|}{ The number of family members } & \multirow{5}{*}{8.388} & \multirow{5}{*}{0.211} \\
\hline$\bullet 1-3$ & 3 & 7 & 12 & 22 & & \\
\hline$\cdot 4-7$ & 10 & 59 & 48 & 117 & & \\
\hline$\bullet 8-10$ & 2 & 21 & 20 & 43 & & \\
\hline - $11-15$ & 0 & 3 & 9 & 12 & & \\
\hline Total & 15 & 90 & 89 & 194 & & \\
\hline
\end{tabular}

*Significant level at 0.05 .

Table 7. Relationship between Level of knowledge and obstetrical history

\begin{tabular}{|c|c|c|c|c|c|c|}
\hline \multirow{2}{*}{ items } & \multicolumn{3}{|c|}{ level of knowledge } & \multirow{2}{*}{ Total } & \multirow{2}{*}{$\mathrm{X}^{2}$} & \multirow{2}{*}{$\mathbf{P}$} \\
\hline & Excellent & very good & Poor & & & \\
\hline \multicolumn{7}{|l|}{ Number of pregnancies } \\
\hline $1-3$ & 7 & 33 & 31 & 71 & \multirow{5}{*}{8.115} & \multirow{5}{*}{0.23} \\
\hline $4-6$ & 5 & 41 & 29 & 75 & & \\
\hline $7-9$ & 3 & 15 & 18 & 36 & & \\
\hline $10-13$ & 0 & 3 & 10 & 13 & & \\
\hline Total & 15 & 92 & 88 & 195 & & \\
\hline \multicolumn{5}{|l|}{ Numbers of deliveries } & \multirow{6}{*}{4.779} & \multirow{6}{*}{0.572} \\
\hline $1-3$ & 7 & 38 & 33 & 78 & & \\
\hline $4-6$ & 7 & 41 & 35 & 83 & & \\
\hline $7-9$ & 1 & 10 & 14 & 25 & & \\
\hline $10-13$ & 0 & 3 & 7 & 10 & & \\
\hline Total & 15 & 92 & 89 & 196 & & \\
\hline \multicolumn{5}{|l|}{ The number of living children } & \multirow{6}{*}{5.083} & \multirow{6}{*}{0.533} \\
\hline $1-3$ & 7 & 36 & 31 & 74 & & \\
\hline $4-6$ & 7 & 41 & 31 & 79 & & \\
\hline $7-9$ & 1 & 10 & 12 & 23 & & \\
\hline $10-13$ & 0 & 2 & 6 & 8 & & \\
\hline Total & 15 & 89 & 80 & 184 & & \\
\hline \multicolumn{5}{|l|}{ Number of abortion } & \multirow{6}{*}{3.919} & \multirow{6}{*}{0.688} \\
\hline once & 1 & 23 & 27 & 51 & & \\
\hline twice & 1 & 8 & 6 & 15 & & \\
\hline three times & 0 & 4 & 6 & 10 & & \\
\hline others & 3 & 13 & 16 & 32 & & \\
\hline Total & 5 & 48 & 55 & 108 & & \\
\hline \multicolumn{5}{|l|}{ Do you go for antenatal care clinic } & \multirow{4}{*}{5.185} & \multirow{4}{*}{0.075} \\
\hline Yes & 14 & 86 & 74 & 174 & & \\
\hline No & 1 & 6 & 15 & 22 & & \\
\hline Total & 15 & 92 & 89 & 196 & & \\
\hline \multicolumn{5}{|l|}{ The month go to care for pregnancy } & \multirow{4}{*}{5.317} & \multirow{4}{*}{0.256} \\
\hline in the first 3 months of pregnancy & 10 & 61 & 43 & 114 & & \\
\hline in the mid 3 months of pregnancy & 1 & 13 & 19 & 33 & & \\
\hline in the last 3 months of pregnancy & 3 & 16 & 19 & 38 & & \\
\hline Total & 14 & 90 & 81 & 185 & & \\
\hline
\end{tabular}


Table 8. Relationship between level of Self-care Practice and Socio-demographic Data of pregnant women

\begin{tabular}{|c|c|c|c|c|c|c|}
\hline \multirow{2}{*}{ Items } & \multicolumn{3}{|c|}{ Level of self-care Practice } & \multirow{2}{*}{ Total } & \multirow{2}{*}{$\mathrm{X}^{2}$} & \multirow{2}{*}{$\mathbf{P}$} \\
\hline & Excellent & very good & Poor & & & \\
\hline \multicolumn{7}{|l|}{ Age (years) } \\
\hline $17-27$ & 3 & 19 & 14 & 36 & \multirow{3}{*}{3.641} & \multirow{3}{*}{0.456} \\
\hline $28-38$ & 12 & 52 & 22 & 86 & & \\
\hline $39-49$ & 6 & 45 & 26 & 77 & & \\
\hline Total & 21 & 116 & 62 & 199 & & \\
\hline \multicolumn{7}{|l|}{ Educational level } \\
\hline primary-secondary & 1 & 5 & 0 & 6 & 15.5 & $0.017^{*}$ \\
\hline intermediate & 0 & 6 & 9 & 15 & & \\
\hline secondary & 3 & 25 & 21 & 49 & & \\
\hline University & 17 & 80 & 32 & 129 & & \\
\hline Total & 21 & 116 & 62 & 199 & & \\
\hline \multicolumn{7}{|l|}{ Professional status } \\
\hline Employee & 19 & 84 & 39 & 142 & 6.11 & $0.047^{*}$ \\
\hline Housewife & 2 & 31 & 23 & 56 & & \\
\hline Total & 21 & 115 & 62 & 198 & & \\
\hline \multicolumn{7}{|l|}{ Income status } \\
\hline less than $5000 \mathrm{SR}$ & 1 & 19 & 16 & 36 & 5.314 & 0.257 \\
\hline 5000 to 10000 SR & 10 & 48 & 25 & 83 & & \\
\hline 10000 and more SR & 10 & 47 & 21 & 78 & & \\
\hline Total & 21 & 114 & 62 & 197 & & \\
\hline \multicolumn{7}{|c|}{ The number of family members } \\
\hline $1-3$ & 2 & 12 & 8 & 22 & 7.257 & 0.298 \\
\hline $4-7$ & 14 & 68 & 35 & 117 & & \\
\hline $8-10$ & 4 & 30 & 9 & 43 & & \\
\hline 11-15 & 1 & 4 & 7 & 12 & & \\
\hline Total & 21 & 114 & 59 & 194 & & \\
\hline
\end{tabular}

*Significant level at 0.05 .

Table 9. Relationship between Level of Self-care Practice and obstetrical history

\begin{tabular}{|c|c|c|c|c|c|c|}
\hline \multirow{2}{*}{ Items } & \multicolumn{3}{|c|}{ level of Practice } & \multirow{2}{*}{ Total } & \multirow{2}{*}{$\mathrm{X}^{2}$} & \multirow{2}{*}{$\mathbf{P}$} \\
\hline & Excellent & very good & Poor & & & \\
\hline Number of pregnancies & & & & & \multirow{6}{*}{10.42} & \multirow{6}{*}{0.108} \\
\hline$\cdot 1-3$ & 6 & 44 & 21 & 71 & & \\
\hline$\cdot 4-6$ & 13 & 39 & 23 & 75 & & \\
\hline$\cdot 7-9$ & 0 & 25 & 11 & 36 & & \\
\hline - $10-13$ & 1 & 6 & 6 & 13 & & \\
\hline Total & 20 & 114 & 61 & 195 & & \\
\hline \multicolumn{5}{|l|}{ Numbers of deliveries } & \multirow{6}{*}{7.19} & \multirow{6}{*}{0.303} \\
\hline$\cdot 1-3$ & 8 & 48 & 22 & 78 & & \\
\hline$\cdot 4-6$ & 12 & 44 & 27 & 83 & & \\
\hline 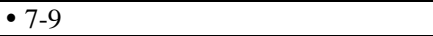 & 0 & 18 & 7 & 25 & & \\
\hline$\cdot 10-13$ & 1 & 4 & 5 & 10 & & \\
\hline Total & 21 & 114 & 61 & 196 & & \\
\hline \multicolumn{5}{|l|}{ The number of living children } & \multirow{6}{*}{9.59} & \multirow{6}{*}{0.143} \\
\hline$\cdot 1-3$ & 7 & 46 & 21 & 74 & & \\
\hline$\cdot 4-6$ & 11 & 42 & 26 & 79 & & \\
\hline$\cdot 7-9$ & 1 & 18 & 4 & 23 & & \\
\hline - $10-13$ & 1 & 2 & 5 & 8 & & \\
\hline Total & 20 & 108 & 56 & 184 & & \\
\hline \multicolumn{5}{|l|}{ Number of abortion } & \multirow{6}{*}{6.53} & \multirow{6}{*}{0.366} \\
\hline - Once & 8 & 26 & 17 & 51 & & \\
\hline - Twice & 3 & 6 & 6 & 15 & & \\
\hline - three times & 0 & 7 & 3 & 10 & & \\
\hline - others & 1 & 19 & 12 & 32 & & \\
\hline Total & 12 & 58 & 38 & 108 & & \\
\hline \multicolumn{5}{|l|}{ Do you go for antenatal care clinic } & \multirow{4}{*}{16.47} & \multirow{4}{*}{$0.001^{* *}$} \\
\hline - Yes & 20 & 109 & 45 & 174 & & \\
\hline - No & 1 & 6 & 15 & 22 & & \\
\hline Total & 21 & 115 & 60 & 196 & & \\
\hline \multirow{2}{*}{$\begin{array}{l}\text { The month go to care for pregnancy } \\
\text { - in the first } 3 \text { months of pregnancy }\end{array}$} & & & & & \multirow{5}{*}{14.81} & \multirow{5}{*}{$0.005^{* *}$} \\
\hline & 16 & 76 & 22 & 114 & & \\
\hline - in the mid 3 months of pregnancy & 3 & 16 & 14 & 33 & & \\
\hline - in the last 3 months of pregnancy & 2 & 18 & 18 & 38 & & \\
\hline Total & 21 & 110 & 54 & 185 & & \\
\hline
\end{tabular}

*Significant level $0.05 * *$ High significant level 0.001 . 
Table 10. Correlation between level of Knowledge and level of Self-care practice

\begin{tabular}{|c|c|c|c|c|c|c|c|c|c|c|c|}
\hline & \multicolumn{6}{|c|}{ Self-care Practice } & \multirow{2}{*}{\multicolumn{2}{|c|}{ Total }} & \multirow{3}{*}{ Spearman Correlation } & \multirow{3}{*}{$\boldsymbol{P}$} \\
\hline & & \multicolumn{2}{|c|}{ Excellent } & \multicolumn{2}{|c|}{ very good } & \multicolumn{2}{|c|}{ Poor } & & & & \\
\hline & & No & $\%$ & No & $\%$ & No & $\%$ & No & $\%$ & & \\
\hline \multirow{3}{*}{ knowledge } & Excellent & 3 & 1.5 & 12 & 6.0 & 0 & 0.0 & 15 & 7.5 & \multirow{4}{*}{0.414} & \multirow{4}{*}{$0.001 *$} \\
\hline & very good & 14 & 7.0 & 64 & 32.0 & 15 & 7.5 & 93 & 46.5 & & \\
\hline & Poor & 4 & 2.0 & 41 & 20.5 & 47 & 23.5 & 92 & 46.0 & & \\
\hline \multicolumn{2}{|l|}{ Total } & 21 & 10.5 & 117 & 58.5 & 62 & 31.0 & 200 & 100.0 & & \\
\hline
\end{tabular}

* High significant level 0.001 .

There is highly significant correlation (Spearman Correlation $=0.414$, p-value $=0.001$ ). They are strong. Positive correlation between knowledge and practice (Table 10)

\section{Discussion}

Good oral health during pregnancy can not only improve the health of the pregnant mother but also potentially the health of the child. The present study aims to assess the knowledge and Self-care practice toward oral health during pregnancy among Saudi women.

The majority of women in this study between 28-38 years old with university degree educational level About $38.5 \%$ of the sample pregnant for 4-6 months and those people need more health education about calcium and vitamin D deficiency and this reflects that the Saudi women like to pregnant for several time, as a maternal nurse must put more attention for these women.

Related to the degree of knowledge about oral health this study shows about $45 \%$ of participants have poor knowledge in state of income state very good and the mother attends in early prenatal care, still this of women high risk group. Study of [16], found that $43 \%$ of women surveyed reported having heard about the possible connection between health in pregnancy and oral health and 39\% thought that tooth and gum problems could affect outcomes of pregnancy.

On other study have shown periodontal disease to be significant risk factor for pregnancy outcomes as preterm low birth weight $[19,25,26]$. In other study mothers were not certain about this relationship, therapy indicating that pregnant women require education on oral health maintenance and the link between oral health of the mother and overall health of the newborn (Turkish Women's self-reported knowledge and behavior towards oral health during pregnancy).

Another finding of this analysis, about (75.5) didn't know about the harmful of brushing the teeth directly after vomiting. The majority of the pregnant women in this study (97 \%) they have toothbrush and about (61.8) they have mistaken. The finding of the present study was (31.7) they didn't use flossing on oral health practice However, there were a few questions on basic oral health that Saudi women missed as the majority of women did not know what plaque was and that the best time to floss is before brushing. This indicates that women were not aware of certain oral health practices that may help reduce periodontal disease, a finding that is also supported by previous studies. This shows that in three different populations, women's oral health knowledge, although adequate in most areas, can use some improvement. This is important information that dentists should know as it may have implications on the information they give women. Furthermore, these women will soon be mothers, who will influence their children's oral health. Although this study was not focused on children's oral health, this issue is one that future research can further explore $[4,8,17,18]$.

According to study among Turkish women's toward oral health during pregnancy, many women do not seek dental care during their pregnancy, and those who do often confront unwillingness by dentists to provide care $[19,20,21]$.

In this study, some of the important knowledge found to be poor among the pregnant women, Like Vomiting with nausea in the first months contain acids damage the outer layer of the teeth while (57.5\%) they didn't know. Nausea and vomiting during pregnancy cause extensive erosion of the tooth surface leading to deteriorating oral health status which has been associated with adverse pregnancy outcomes such as pre-term births, development of pre-eclampsia and delivery of a "small-for-gestational-age" infant. It is imperative however; that management of nausea and vomiting should involve measures targeted at reducing the effects of the hydrochloric acid content of gastric juice on the teeth as well as improve oral hygiene practices to prevent poor oral health [22,23,24].

In the present study there was a significant relationship between the level of self-care practice about oral health during pregnancy and level of knowledge, the majority of women did not know what plaque was and that the best time to floss is before brushing. This indicates that women were not aware of certain oral health practices that may help reduce periodontal disease, a finding that is also supported by previous studies $[27,28]$. This represent that three different populations, women's oral health knowledge, although adequate in most areas, can use some improvement. This is important information that dentists should know as it may have implications on the information they give women. Furthermore, these women will soon be mothers, who will influence their children's oral health. Although this study was not focused on children's oral health, this issue is one that future research can further explore $[1,29,30]$ Saudi women's knowledge was lacking in certain important areas of oral health Self-care practices specific to pregnancy. For example, most women did not know that pregnancy a reason of why Saudi women were not aware of these pregnancy-specific oral health practices. By not attending dental check-ups, they may be missing out on receiving pertinent information from their dentists. Previous studies have also found that women tend to decrease or stop attending dental 
check-ups during their pregnancy. Thus, it is important for dentists and health care practitioners to recognize that even women with dental insurance and regular dental check-up attendance before pregnancy may still need to be encouraged to continue during pregnancy [8,32,33,34].

Previous studies have shown periodontal disease to be a significant risk factor for pregnancy outcomes such as pre -term low birth weight .In the present study, mothers were not certain about this relationship, thereby indicating that pregnant women require education on oral health maintenance and link between oral health of the mother and overall health of the new born [35,36].

According to the association of women's health, Obstetric and neonatal nurses American Academy of Pediatric Dentistry [37], stated most of the mothers do not go for dental care during pregnancy, In addition, only 34\% of Medicaid - insured pregnant women see a dentist, whereas 55\% of pregnant women with private insurance carriers do. The finding of the present study indicated about (65.2) of pregnant women didn’t go to dental clinic during their pregnancy.

The oral health guidelines encourage dentists to provide regular dental care for pregnant women and recommends that prenatal practices initiate oral health programs at time of prenatal visit. They also stress the importance of active communication between dental, prenatal and paediatric care providers for purposes of better risk assessment, referral and intervention [14,38,39,40].

\section{Conclusions and Recommendations}

Saudi pregnant women, despite having knowledge that adverse pregnancy events related to oral health, didn't seek oral care during pregnancy. We can less likely to have dental problems during pregnancy if you already have good oral hygiene habits. Prenatal care offers one of the best time for addressing oral health in Saudi pregnant women, with each prenatal visit are scheduled. And the visit focus on, oral health care, treatment and education.

\section{Recommendations}

Developing health education programme should be built in to antenatal care unit, primary health care and hospital. Conduct careful screening of oral risks, and assist women in obtaining regular dental care are essential elements of oral health in prenatal programs.

\section{References}

[1] National Organization of Nurse Practitioner Faculties. (2014). Nurse practitioner core competencies with suggested curriculum content. Retrieved from

http://c.ymcdn.com/sites/nonpf.siteym.com/resource/resmgr/Comp etencies/NPCoreCompsContent FinalNov20.pdf.

[2] Ozen, B., Ozer, L., Başak, F., Altun, C., \& Açıkel, C. (2012). Turkish women's self-reported knowledge and behavior towards oral health during pregnancy. Med Princ Pract, 21(4), 318-322.

[3] George A, Shamim S, Johnson M, Ajwani S, Bhole S, Blinkhorn A. Periodontal treatment during pregnancy and birth outcomes: A meta-analysis of randomised trials. Int $\mathrm{J}$ Evid Based Healthc. (2011); 9: 122-47.
[4] Shenoy R, Chacko V. Utilization of dental services due to dental pain by pregnant women in India: A qualitative analysis. J Interdiscip Dent. (2013); 3: 18-20.

[5] Alves, R., Ribeiro, R., Costa, L., Leles, C., Freire, M., \& Paiva, S. Oral Care during Pregnancy: Attitudes of Brazilian Public Health Professionals. [Article]. International Journal of Environmental Research and Public Health, (2012) 9(10), 3454-3464.

[6] Hashim, R., \& Akbar, M. (2014). Gynecologists' knowledge and attitudes regarding oral health and PD leading to adverse pregnancy outcomes. Journal of International Society of Preventive \& Community Dentistry, 4(Suppl. 3), S166-S172.

[7] Sheha E., Hassan H., Gamel W. Association between pre-pregnant overweight and obesity and periodontal disease during pregnancy: a cross sectional study. International Journal of Studies in Nursing. 2018; 3(1): 1-21.

[8] Wu, M., Chen, S.-W., \& Jiang, S.-Y. Relationship between gingival inflammation and pregnancy. Mediators of Inflammation, 2015, 623427.

[9] Corbella, S., Taschieri, S., Del Fabbro, M., Francetti, L., Weinstein, R., \& Ferrazzi, E. Adverse pregnancy outcomes and periodontitis: A systematic review and meta-analysis exploring potential association. Quintessence International, (2016).47(3), 193-204.

[10] Eke, P. I., Dye, B. A., Wei, L., Thornton-Evans, G. O., \& Genco, R. J.. Prevalence of periodontitis in adults in the United States: 2009 and 2010. Journal of Dental Research, (2012) 91(10), 914-920.

[11] Gogeneni, H., Buduneli, N., Ceyhan-O“ ztu“rk, B., Gu“mu“s, , P., Akcali, A., Zeller, I., O” zc,aka, O“. Increased infection with key periodontal pathogens during gestational diabetes mellitus. Journal of Clinical Periodontology, (2015). 42(6), 506-512.

[12] Raman deep, Singh Gambhir, Ashutosh Nirola, Tarun Gupta, Tegbir Singh Sekhon, Samir Anand (2015) Oral health knowledge and awareness among pregnant women in India: A systematic review.

[13] Erin Hartnett, Judith Haber, Barbara Krainovich-Miller, Abigail Bella, Anna Vasilyeva, and Julia Lange Kessle ; Oral Health in Pregnancy JOGNN, 45, 565-573 July-August 2016, Pages 565573.

[14] Haber, J., Hartnett, E., Allen, K., Hallas, D., Dorsen, C., LangeKessler, J. Wholihan, D. Putting the mouth back in the head: HEENT to HEENOT. American Journal of Public Health, (2015).105(3), 437-441.

[15] Cigna Corporation. Healthy smiles for mom and baby: Insights into expecting and new mothers' oral health habits. Retrieved from

http://www.cigna.com/assets/docs/newsroom/cigna-study-healthysmiles-for-mom-and-baby- (2015).

[16] Vt, H., T, M., T, S., Nisha V, A., \& A, A.. Dental considerations in pregnancy-a critical review on the oral care. J Clin Diagn Res, (2013) 7(5), 948-953.

[17] Azofeifa, A., Yeung, L. F., Alverson, C. J., \& Beltra'n-Aguilar, E. Oral health conditions and dental visits among pregnant and nonpregnant women of childbearing age in the United States, National Health and Nutrition Examination Survey, 1999-2004. Preventing Chronic Disease, (2014). 11, E163.

[18] Jiang, H., Xiong, X., Buekens, P., Su, Y., \& Qian, X. (2015). Use of mouth rinse during pregnancy to improve birth and neonatal outcomes: a randomized controlled trial. BMC Pregnancy Childbirth, 15(1), 311

[19] Buerlein J, Peabody H, Santoro K. NIHCM Foundation. Improving Access to Perinatal Oral Health Care: Strategies and Considerations for Health Plans: Issue Brief July 2010. National Institute for Health Care Management. Available from: www.nihcm.org/pdf/NIHCM-OralHealth-Final.pdf. [Last accessed on 2014 Dec 01].

[20] George A, Johnson M, Blinkhorn A, Ajwani S, Bhole S, Yeo AE,. The oral health status, practices and knowledge of pregnant women in south-western Sydney. Aust Dent J. 2013; 58: 26-33.

[21] Bamanikar S, Kee LK. Knowledge, attitude and practice of oral and dental healthcare in pregnant women. Oman Med J. (2013); 28: 288-91.

[22] Paul Y, Singh P, Singla P, Rathore S, Vaid R. (2014) Periodontal health - Awareness among pregnant females in semi urban population of Chandigarh - A cross-sectional survey. BFUDJ; 5: 49-53. 
[23] Ha, J. E., Jun, J. K., Ko, H. J., Paik, D. I., \& Bae, K. H.. Association between periodontitis and preeclampsia in neversmokers: A prospective study. Journal of Clinical Periodontology, (2014) 41(9), 869-874.

[24] Chacko V, Shenoy R, Prasy HE, Agarwal S. Self-reported awareness of oral health and infant oral health among pregnant women in Mangalore, India - A prenatal survey. Int J Health Rehabil Sci(2103).; 2: 109-15.

[25] American Academy of Pediatric Dentistry.. Policy on early childhood caries (ECC): Classifications, consequences, and preventive strategies. Pediatric Dentistry, (2015) 37(6), 50-52.

[26] Mital P, Agarwal A, Raisingani D, Mital P, Hooja N, Jain P. (2013) Dental caries and gingivitis in pregnant women. Sch Acad J Biosci. 2013; 1: 718-23.

[27] Saddki, N., Yusoff, A., \& Hwang, Y.L. (2010). Factors associated with dental visit and barriers to utilization of oral health care services in a sample of antenatal mothers in Hospital University Sains Malaysia. BMC Public Health, 10, 75. Retrieved from http://www.ncbi.nlm.nih.gov/pmc/articles/PMC2834630/pdf/1471 -2458-10-75.pdf.

[28] Agarwal A, Mital P, Hooja N, Mital P, Salvi A, Fatima A. Oral and dental health knowledge, attitude and practice among pregnant Women. Sch Acad J Biosci. (2014); 2: 627-32.

[29] American College of Obstetricians and Gynecologists Women's Health Care Physicians Committee on Health Care for Underserved Women. (2013). Committee opinion no. 569: Ora health care during pregnancy and through the lifespan. Obstetrics and Gynecology, (2013). 122(2 Pt. 1), 417-422.

[30] Buerlein, J. K., Horowitz, A. M., \& Child, W. L. Perspectives of Maryland women regarding oral health during pregnancy and early childhood. Journal of Public Health Dentistry, (2011). 71(2), 131-135.

[31] Chacko, V., Shenoy, R., Prasy, H. E., \& Agarwal, S.. Self-reported awareness of oral health and infant oral health among pregnant women in Mangalore, India - a prenatal survey. International
Journal of Health and Rehabilitation Sciences, (2013) 2(2), 109115.

[32] Ehlers, V., Callaway, A., Hortig, W., Kasaj, A., \& Willershausen, B. Clinical parameters and aMMP-8-concentrations in gingival crevicular fluid in pregnancy gingivitis. Clinical Laboratory, (2013). 59(5-6), 605-611.

[33] Farg D. and Hassan H. Risk Factors for Hyperemesis Graviderum Requiring Hospital Admission during Pregnancy and Nursing Implication. American Journal of Nursing Research, 2019; 7(3).

[34] Hughes SC, Levinson G, Rosen MA, Schnider and Levinson's Anesthesia for Obstetics, 4th ed. 2001. Lippincott Williams \& Wilkins :Philadelphia.

[35] Institute of Medicine. (2013). Oral health literacy: Workshop summary. Washington, DC: The National Academies Press. Retrieved-from http://iom.nationalacademies.org/Reports/2013/OralHealthLiteracy.aspx.

[36] Journal of Indian Society of Periodontology Vol 19, Issue 6, NovDec www.jisponline.com on Wednesday, April 18, 2018.

[37] Keirse, M. \& Plutzer, K. (2010). Women's attitudes to and perceptions of oral health and dental care during pregnancy. J Perinat Med, 38(1), 3-8.

[38] Langelier, M. H., Glicken, A. D., \& Surdu, S. (2015). Adoption of oral health curriculum by physician assistant education programs in 2014. The Journal of Physician Assistant Education, 26(2), 60-69.

[39] Reddy RS, Amara SL, Tatapudi R, Koppolu P, Nimma VL, Reddy RL (2013). Awareness and attitude towards maintenance of oral health during pregnancy among patients and clinicians attending obstetrics and gynecology ward. J Dr NTR Univ Health Sci.; 2: 102-8.

[40] Pentapati KC, Acharya S, Bhat M, Rao SK, Singh S. (2013). Knowledge of dental decay and associated factors among pregnant women: A study from rural India. Oral Health Prev Dent.; 11: 161-8.

(C) The Author(s) 2019. This article is an open access article distributed under the terms and conditions of the Creative Commons Attribution (CC BY) license (http://creativecommons.org/licenses/by/4.0/). 